\title{
Analysis of DNA-Phosphate Adducts In Vitro Using Miniaturized LC-ESI-MS/MS and Column Switching: Phosphotriesters and Alkyl Cobalamins
}

\author{
Johanna Haglund, * Walter Van Dongen, Filip Lemière, \\ and Eddy L. Esmans \\ Nucleoside Research and Mass Spectrometry Unit, Department of Chemistry, University of Antwerp, Antwerp, \\ Belgium
}

\begin{abstract}
DNA-phosphate adducts are known to be formed by a variety of alkylating agents. Due to little or no repair of DNA-phosphate adducts, these adducts may offer increased possibilities of both identifying and quantifying DNA adducts. The formation of DNA-phosphate adducts leads to a complete esterification of the phosphate group giving rise to a phosphotriester configuration. This work consists of the characterization of ethyl phosphotriesters (Ethyl PTE) using miniaturized LC-ESI-MS/MS and column switching in enzymatic hydrolysate of DNA treated in vitro with the model compound $N$-ethyl- $N$-nitrosourea (ENU). In vitro ENU-treated DNA was enzymatically degraded using nuclease P1, phosphodiesterase, and alkaline phosphatase. The use of column switch allowed for large-volume injections, where unmodified nucleosides were discarded in the loading step. The analytes were forward flushed to the analytical column in the eluting step and separated using a linear gradient. Ten different ethyl PTEs (dGpEtdG, dApEtdA, dCpEtdC, TpEtT, dGpEtdA, dGpEtdC, dGpEtT, dApEtdC, $\mathrm{dApEtT}$, and $\mathrm{dCpEtT)}$ were characterized by their masses and CAD product ion spectra. Measurements of accurate masses were carried out yielding experimental masses within 5 ppm of the calculated masses for 9 of the 10 ethyl PTEs. For comparison, the enzymatic hydrolysate of ENU-treated DNA was subjected to transalkylation of the DNA-phosphate adducts by cob(I)alamin. Formed ethyl-cobalamins were analyzed according to earlier developed methods. The limit of detection of an alkyl-cobalamin standard and an alkyl PTE standard was $2 \mathrm{fmol}$ and $5 \mathrm{fmol}$, respectively. (J Am Soc Mass Spectrom 2004, 15, 593-606) (C) 2004 American Society for Mass Spectrometry
\end{abstract}

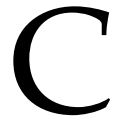
hemical reactivity was early recognized as a major determinant of chemical toxicity. Thus, chemical substances that are reactive or give rise to reactive metabolites may lead to negative effects in humans. In principle, all known initiators of chemical carcinogenesis are electrophilically reactive and most are alkylating agents. These electrophilically reactive compounds are prone to react with different nucleophilic atoms in macromolecules in the body forming reaction products, so-called adducts [1]. The reaction with atoms in DNA causes premutagenic events such as adducts to guanine- $\mathrm{O}^{6}$ and thymine- $\mathrm{O}^{2}$ and $-\mathrm{O}^{4}$, DNA thus being the key target molecule in chemical carcinogenesis [2-4]. These adducts are repaired at rates which vary between species, organs, tissues, cells, etc. [5, 6],

Published online February 10, 2004

Address reprint requests to Dr. J. Haglund, Department of Environmental Chemistry, Stockholm University, Svante Arrheniusväg 12, Stockholm 106 91, Sweden. E-mail: johanna.haglund@mk.su.se

*Also affiliated with the Department of Environmental Chemistry, Stockholm University, Stockholm, Sweden. but can still act as markers of exposure to these reactive compounds. On the other hand, using the adduct level as a quantitative measure, as the dose of a reactive chemical in target organs, the rate of turnover of that particular adduct has to be taken into consideration [7].

Most work on DNA adducts has focused on DNAbase adduct measurements and little on the adducts to phosphate groups in DNA. DNA-phosphate adducts are known to be formed by a variety of alkylating agents and are subject to no or little repair [5], which results in accumulation [6]. This indicates, that an analysis of DNA-phosphate adducts may offer increased possibilities of both identifying and quantifying DNA adducts. Esterification of the phosphate oxygen by alkylation will lead to formation of a phosphotriester configuration (PTE). PTEs are chemically stable under physiological conditions unless the alkyl group contains an oxygen, a sulfur or a nitrogen in the $\beta$-position in regard to the ester linkage $[8,9]$. Early efforts to measure PTEs in DNA utilized the fact, shown by Miller et al. [10], that methyl and ethyl PTEs in DNA 
Enzymatic cleavage by $5^{\prime}$-nuclease

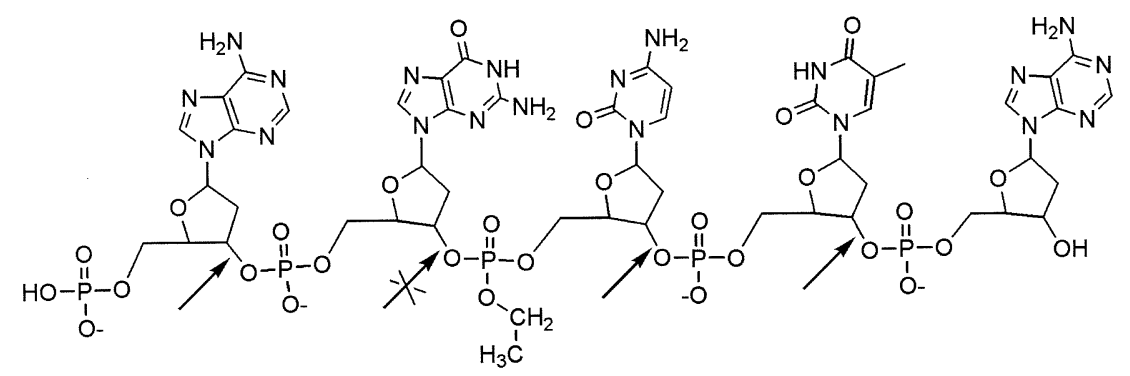

Products after nuclease treatment of DNA<smiles>CCOP(=O)(OCC1OC(n2ccc(N)nc2=O)CC1O)OC1CC(n2cnc3c(=O)[nH]c(N)nc32)OC1COP(=O)(O)O</smiles>

Phosphate-ethylated dinucleotide

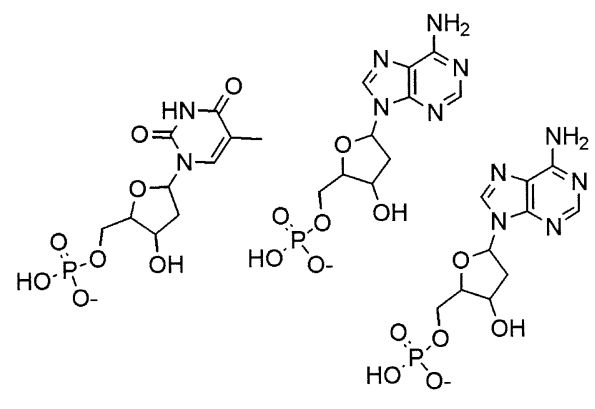

Nucleotides

Products after additional alkaline phosphatase treatment of DNA

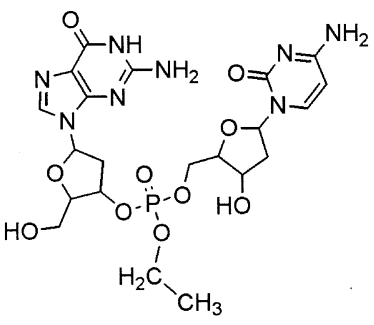

Ethyl phosphotriester<smiles>Cc1cn(C2CC(O)C(CO)O2)c(=O)[nH]c1=O</smiles>

Nucleosides

Figure 1. Illustration of the resistance to nucleases of the ester bond adjacent to an alkylated phosphate oxygen.

were resistant to hydrolysis by certain nucleases. The enzymes that normally hydrolyse diester bonds are not capable of cleaving the internucleotide bonds adjacent to a completely esterified phosphate group (Figure 1).

For instance, already in 1978 Swenson and Lawley measured, after enzymatic hydrolysis, methyl and ethyl PTEs in DNA treated with radiolabeled alkylating agents [11]. In the 1990s some efforts were also done to determine PTEs in DNA by the ${ }^{32} \mathrm{P}$-postlabeling method $[12,13]$. Since the PTEs themselves are not substrates for the T4 polynucleotide kinase used for the ${ }^{32} \mathrm{P}$-phosphorylation due to the absence of a negative charge of one of the phosphate oxygens, the original method was modified. The modification comprised of alkaline hydrolysis of the PTEs after enzymatic degradation in order to obtain a free negatively charged oxygen. This treatment is expected to result in hydrolysis of the adduct. During the last decade there has been a large increase in the use of LC coupled to mass-spectrometric detection for direct analysis of DNA-base adducts [14, 15]. In addition, applying several new techniques such as miniaturization of LC and column switching enables analysis of low levels of DNA adducts in complex biological matrices [16]. However, there has not been much focus on phosphate adducts in DNA.

This paper presents characterization of DNA-phosphate adducts as alkyl phopshotriesters in DNA by capillary LC-ESI-MS/MS. For this purpose calf thymus DNA treated in vitro with $N$-ethyl- $N$-nitrosourea, a model substance giving rise to relatively high levels of phosphate adducts, has been used. The alkylated DNA was subject to enzymatic degradation using nuclease 
P1, phosphodiesterase and alkaline phosphatase. The hydrolysate was filtered with molecular weight cut-off filters and analyzed using capillary LC-ESI-MS/MS without further sample preparation. Ten different possible ethyl PTEs were characterized by their accurate masses and low-energy CAD product-ion spectra. For comparison, identical DNA hydrolysate was analyzed using an independent method, the so-called transalkylation method. This method comprises of specific transfer of DNA-phosphate adducts to the nucleophilic co$\mathrm{b}(\mathrm{I})$ alamin $[17,18]$. The resulting ethyl cobalamins (Et$\mathrm{Cbl}$ ) were analyzed according to an earlier report [19].

\section{Experimental}

\section{Materials}

Thymidine 3'-[thymidine 5'-(methyl phosphate)] (Tp$\mathrm{MeT}$ ) was a product from Campro Scientific (Stockholm, Sweden). Hydroxy cobalamin, methyl cobalamin, DNA (calf thymus), nuclease P1 (EC 3.1.30.1), phosphodiesterase I (EC 3.1.4.1), alkaline phosphatase (EC 3.1.3.1), ammonium hydrogenbicarbonate and $N$-ethyl$\mathrm{N}$-nitrosourea were purchased from Sigma-Aldrich (St Louis, MO). Ammonium acetate, tris(hydroxymethylaminomethane, sodium acetate, trifluoroacetic acid, acetonitril (ACN) and HPLC water were products of Acros Organics (Geel, Belgium). The absolute ethanol was purchased from Fluka (WVR, Leuven, Belgium). HPLC water was used in all experiments. Microcon (YM-10 and YM-30) centrifugal filter devices were purchased from Millipore Corporation (Bedford, MA). All samples and mobile phases were filtered using a $0.2 \mu \mathrm{m}$ nylon syringe filter (Alltech, Lokeren, Belgium) prior to analysis. Caution: The $N$-ethyl- $N$-nitrosourea is not listed as a carcinogen but is an alkylating agent with similar reactivity as the corresponding $N$-methyl- $N$ nitrosourea, a compound listed as a carcinogen.

\section{Treatment of Calf Thymus DNA with N-Ethyl-N- Nitrosourea}

Calf thymus DNA was dissolved in Tris- $\mathrm{HCl}$ buffer $(0.46 \mathrm{M} ; \mathrm{pH}$ 8). A stock solution of the alkylating agent (ENU) was prepared $(60 \mathrm{mM})$ and added to the DNA solution (1:1). The solution was incubated at $37^{\circ} \mathrm{C}$ for $3 \mathrm{~h}$. To precipitate the DNA, $\mathrm{NH}_{4} \mathrm{OAc}$ was added $(0.1$ vol, $3 \mathrm{M}$ ) and the sample was cooled on ice followed by addition of ice-cold ethanol (2 vols). The samples were placed in a freezer for a few hours. The DNA was dissolved in water and reprecipitated according to the above. Samples were centrifuged (5000 g; $10 \mathrm{~min}$ ) and the supernatant was removed. The pellet was used for enzymatic hydrolysis.

\section{Enzymatic Hydrolysis of Alkylated DNA}

The DNA (control and treated) was dissolved in Tris$\mathrm{HCl}$ (1-1.3 mg DNA/mL; $1 \mathrm{mM}$; $\mathrm{pH} 7.4$ ) and hydro- lyzed according to Crain et al. [20], except for a slightly increased treatment time due to the higher DNA concentrations. Firstly, $\mathrm{NH}_{4} \mathrm{OAc}$ was added ( 0.1 vol; $0.1 \mathrm{M}$; $\mathrm{pH}$ 5.3) followed by Nuclease P1 ( $80 \mathrm{u} / \mathrm{mg}$ DNA). The mixture was incubated for $2.5 \mathrm{~h}$ at $45^{\circ} \mathrm{C}$ following addition of ammonium hydrogenbicarbonate ( $0.1 \mathrm{vol} ; 1$ $\mathrm{M})$ and phosphodiesterase $(0.08 \mathrm{u} / \mathrm{mg}$ DNA). The mixture was incubated for $2.5 \mathrm{~h}$ at $37^{\circ} \mathrm{C}$. Finally alkaline phosphatase was added (20 $\mathrm{u} / \mathrm{mg}$ DNA) and the mixture was incubated for $1.5 \mathrm{~h}$ at $37^{\circ} \mathrm{C}$. Samples were filtered using molecular weight cut-off filter (YM-10 or YM-30) and placed in the freezer until used in the transalkylation reaction using cob(I)alamin or in direct analysis of ethyl phosphotriesters.

\section{Transalkylation by Cob(I)Alamin}

The hydrolysate of ENU-treated DNA was transalkylated using cob(I)alamin according to an earlier developed method [17]. DNA sample $(100 \mu \mathrm{L})$ was added to a reduced cobalamin solution under argon. After 30 min the samples were directly analyzed using the same miniaturized LC-ESI-MS/MS and column switching method as for ethyl PTE, developed for alkyl cobalamins [19].

\section{Chromatography}

A column-switching technique developed for analysis of alkyl-cobalamins [19] was used in this paper for the alkyl-cobalamins and the phosphotriesters. The modified cobalamin as well as the modified DNA residues are selectively captured on a pre-column, discarding unmodified residues, following elution to the analytical column for separation. Pre-column $(300 \mu \mathrm{m} \times 5 \mathrm{~mm}$, PepMap, $5 \mu \mathrm{m})$ and analytical column $(300 \mu \mathrm{m} \times 50$ $\mathrm{mm}$, Inertsil ODS-3, $5 \mu \mathrm{m})$ were purchased from LCPackings (Amsterdam, The Netherlands). A capillary LC-system (CapLC, Micromass) was used together with a 10-port valve (coupling see Figure 2). The pre-column was directly connected to the capillary column, all mounted on the 10-port valve utilizing a column switch together with a forward flush over to the analytical column.

Mobile phases used were (A) ACN/water (5:95 vol/ vol), 0.1\% TFA, (B) ACN/water (70:30 vol/vol), 0.1\% TFA, and (C) ACN/water (5:95 vol/vol), 0.1\% TFA. The program used was the following: Samples were injected on the pre-column using the auxiliary system $C$ at 15-20 $\mu \mathrm{L} / \mathrm{min}$. At the same time the binary system $\mathrm{A} / \mathrm{B}$ pumps $20 \%$ Solvent B at a flow of $2-8 \mu \mathrm{L} / \mathrm{min}$ over the analytical column. Three to five min after injection the 10-port valve switches to the eluting position where the binary system A/B forward flushes the pre-column at 2-8 $\mu \mathrm{L} / \mathrm{min}$ using a gradient elution (at time of switching, 20\% B increasing linearly with $5.3 \%$ B per min) with or without programmed regeneration. The different times of switching the valve to eluting position depended on the injection volume of the sample below. In 


\section{Loading position:}

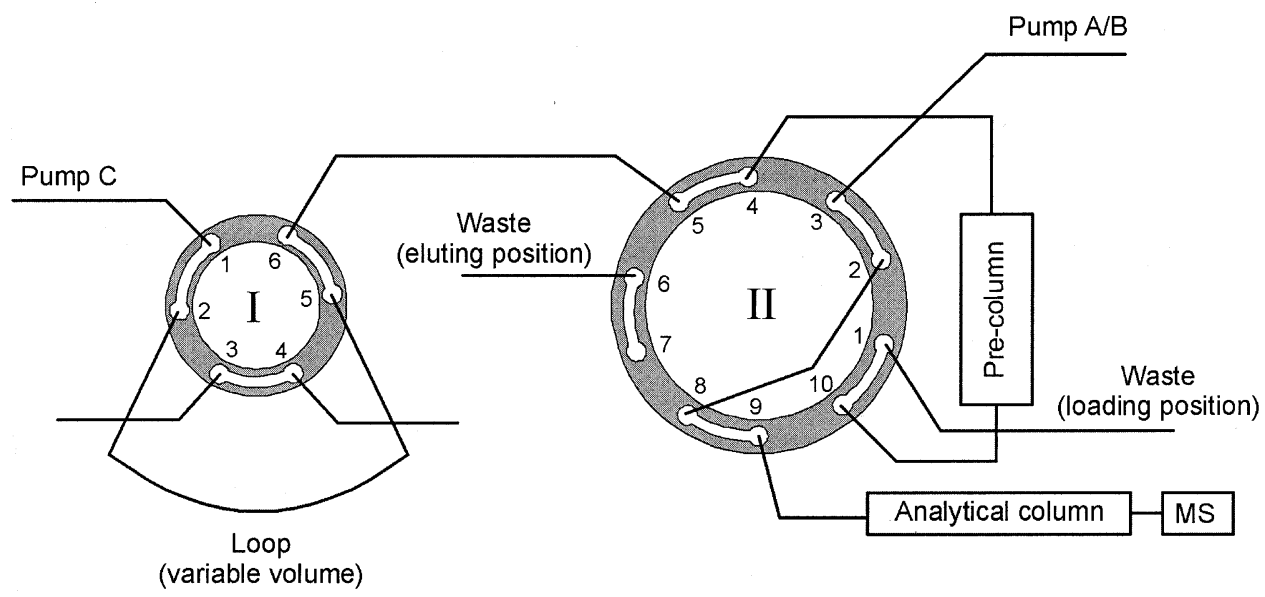

\section{Eluting position: Forward flush}

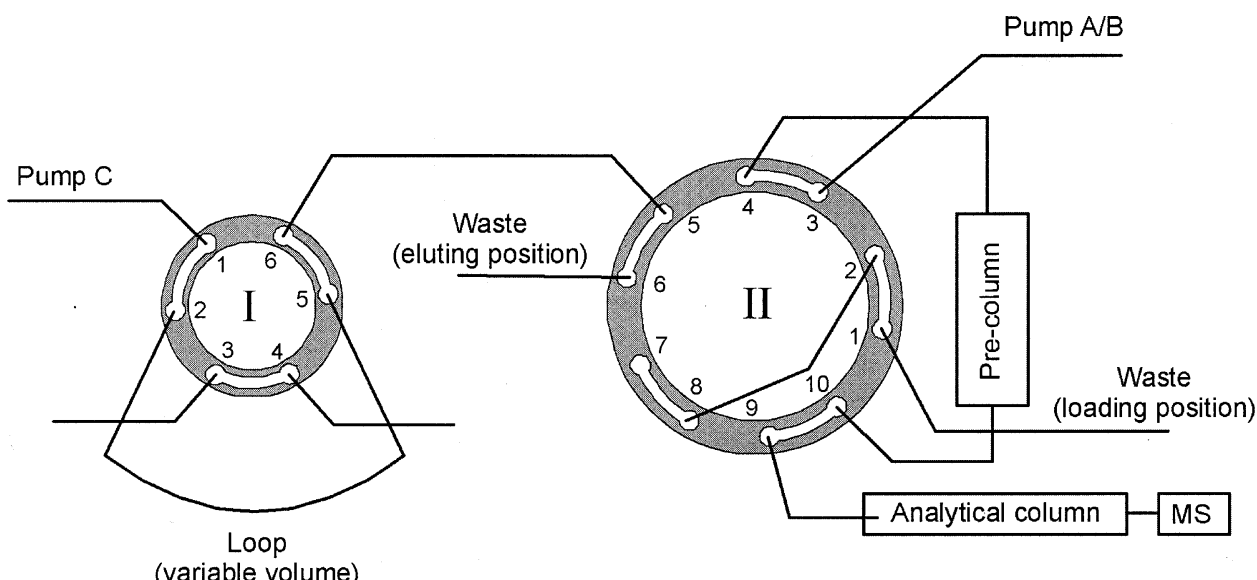

Figure 2. Illustration of the column-switching setup used in this work. The loading position where the sample is passed over the pre-column by Pump C, and the elution position where the sample is flushed forward from the pre-column to the analytical column by the Pump A/B.

the studies of potential isomerism the same system was used, but the gradient was changed to an increase of $2.5 \%$ of Solvent B per min. Lower flow-rate $(4 \mu \mathrm{L} / \mathrm{min})$ over the analytical column was tested using the same gradient $(5.3 \% \mathrm{~B}$ per $\mathrm{min})$ in order to obtain more scans and consequently a better signal to noise ratio.

\section{Mass Spectrometry}

For the qualitative work on analysis of ethyl PTE mass spectra were recorded on a Q-Tof 2 instrument since higher resolution was required. For the quantitative work (LOD measurements) on standards, a Quattro II triple quadropole mass spectrometer was used (Micromass, Manchester, UK) in MRM mode. The instruments were fitted with an atmospheric pressure ionization (API) source that was equipped with a pneumatically assisted Z-spray source. Throughout this work electrospray mass spectra were recorded in the positive ion mode (ESI+). Nitrogen was used as both nebulizing and drying gas at flow-rates of 20 and $300 \mathrm{~L} / \mathrm{h}$, respectively. Low-energy collision-activated dissociation (CAD) spectra were recorded using argon as the collision gas (gas cell pressure of $4 \times 10^{-3} \mathrm{mbar}$ ). For collision energies see the respective experiments.

Both mass spectrometers were directly connected to a capillary LC-system (CapLC, Micromass). The capillary LC outlet was connected to the MS inlet, a standard electrospray probe, and the voltage on the stainless steel capillary was set at 3.3 and 3.5 for the Q-Tof 2 and Quattro-II, respectively. The ion source temperature was $80^{\circ} \mathrm{C}$. The instruments were used in full-scan mode and MS/MS modes (Quattro-II, MRM; Q-Tof 2, product ion scan). In the full-scan mode a mass range from $\mathrm{m} / \mathrm{z}$ 250-800 for the alkyl PTE and $m / z$ 500-1500 for the alkyl-cobalamins, was acquired over 1 and $1.5 \mathrm{~s}$, respectively. Mass spectral data were acquired in a continuum mode. Acquisition and processing of data from the 
mass spectrometer were performed using MassLynx 3.5 (Micromass).

\section{Accurate Mass Measurement}

Accurate mass measurements were recorded on the Q-Tof 2 mass spectrometer using the chromatographic and mass spectrometric conditions specifically described in Results and Discussion. The standard methyl PTE, thymidine 3'-[thymidine 5'-(methyl phosphate)], (TpMeT), was added post-column by syringe infusion at a flow-rate of $5 \mu \mathrm{L} / \mathrm{min}$. Initially, accurate mass measurements were carried out on the product ions of the methyl PTE standard using the precursor ion as lock mass. Secondly, accurate mass measurements of the analytes (ethyl PTE) were carried out, also using the methyl PTE precursor ion as lock-mass. The exact masses of the product ions of each ethyl PTE were determined using their respective precursor ion as lock-mass. The cone voltage $(\mathrm{CV})$ was $20 \mathrm{~V}$ and the collision energy was $15 \mathrm{eV}$ for the ethyl PTE measurements, whereas for the methyl PTE standard, data was acquired using different cone voltages (20-30 V) and collision energies (15-20 eV) in order to aquire accurate mass measurements of several product ions.

\section{Results and Discussion}

\section{General procedure}

The objective of the study was the detection and characterization of phosphate adducts as PTE in in vitrotreated DNA. For comparison, phosphate adducts in the ENU-treated DNA were analyzed using the earlier developed transalkylation method where cob(I)alamin is used for transfer of DNA-phosphate adducts to form alkyl-cobalamin. The complete approach is summarized in Scheme 1.

\section{Ethyl Cobalamin Analysis}

An LC-ESI-MS/MS method was developed for analysis of alkyl-cobalamins in complex mixtures [19], where ethyl cobalamins (Et-Cbls) were shown to be formed in the transalkylation of enzymatic hydrolysate of calf thymus DNA treated in vitro with the ethylating agent $N$-ethyl-N-nitrosourea. The same method was used here to measure Et-Cbls formed in the transalkylation of DNA hydrolysate, the identical DNA hydrolysate being subject to PTE analysis.

The transalkylation reaction mixture $(20 \mu \mathrm{L})$ was injected without prior separation and measured in full scan and in MRM mode. In Figure 3, the ion chromatogram from an MRM run of the Et-Cbl is shown. Et-Cbl was measured $\left(t_{R}=4.9 \mathrm{~min}\right)$ using three cobalaminspecific channels $(679>359,679>665,679>971)$, all starting from the doubly charged protonated molecule $[\mathrm{M}+2 \mathrm{H}]^{2+}$.

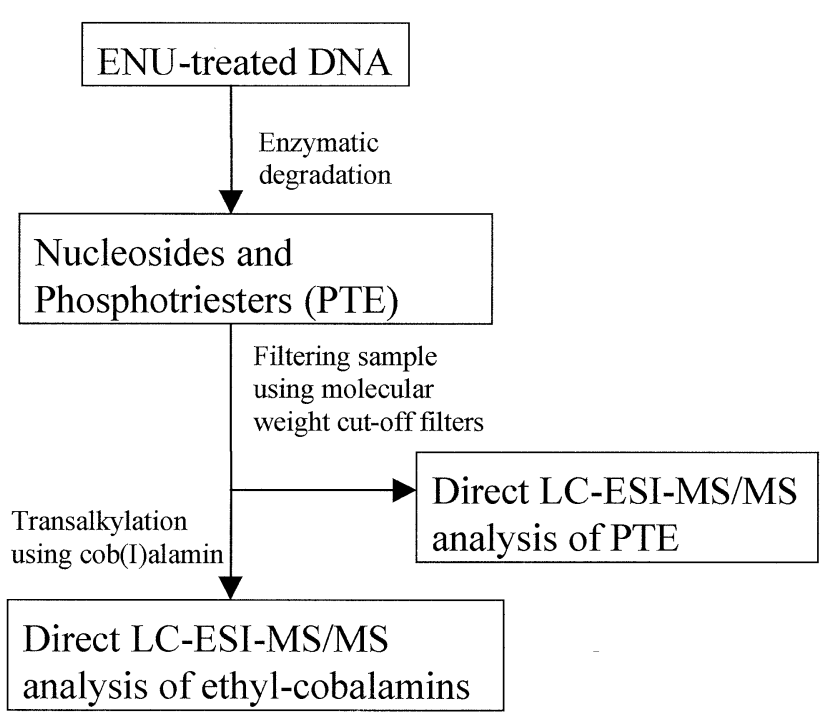

Scheme 1. The procedure of analysis of DNA-phosphate adducts in ENU-treated DNA as ethyl cobalamins and ethyl PTE, respectively.

\section{Phosphotriesters (PTE) Analysis}

The methyl PTE standard. Initially a methyl PTE standard (thymidine $3^{\prime}$-[thymidine $5^{\prime}$-(methyl phosphate)], TpMeT) was studied. In full scan the $[\mathrm{M}+\mathrm{H}]^{+}(\mathrm{m} / \mathrm{z}$ 561) was the only ion observed (data not shown). This ion was used as the precursor in the product ion scan (Figure 4). The product ion spectrum (Figure 4) revealed several fragments specific with regard to phosphate alkylation. Suggested fragmentation pattern is shown in Figure 5.

Detection of Ethyl PTEs in ENU-Treated DNA. The expected masses of the singly charged molecular ions of the ten possible phosphotriesters (dGpEtdG, dApEtdA, dCpEtdC, TpEtT, dGpEtdA, dGpEtdC, dGpEtT, dApEtdC, dApEtT, and dCpEtT) were calculated (Table 1).

Full scan analysis of the enzymatic hydrolysate of ENU-treated DNA $(50 \mu \mathrm{L})$ was performed and the reconstructed ion chromatograms on calculated masses $\left([\mathrm{M}+\mathrm{H}]^{+}\right)$showed five $(\mathrm{m} / \mathrm{z} 560,584,600,593$, and 609) out of ten masses of the ethyl PTEs, indicating their presence.

For the purpose of detecting all ten ethyl PTEs and to record an informative product ion spectrum later on, the concentration sensitivity of the system was enhanced by using large-volume injections (100-200 $\mu \mathrm{L})$. This large volume corresponds to 100-200 $\mu \mathrm{g}$ DNA injected as a pool of nucleosides and ethyl PTEs. These larger injection volumes were injected on the precolumn at a flow-rate of $20 \mu \mathrm{L} / \mathrm{min}$ (System C). The column switching was done for 100 and $200 \mu \mathrm{L}$ injections at 6 and $12 \mathrm{~min}$, respectively. The flow-rate over the analytical column was changed to $4 \mu \mathrm{L} / \mathrm{min}$ without loss of any chromatographic integrity. The masses of all ten ethyl PTEs were detected and eluted within 


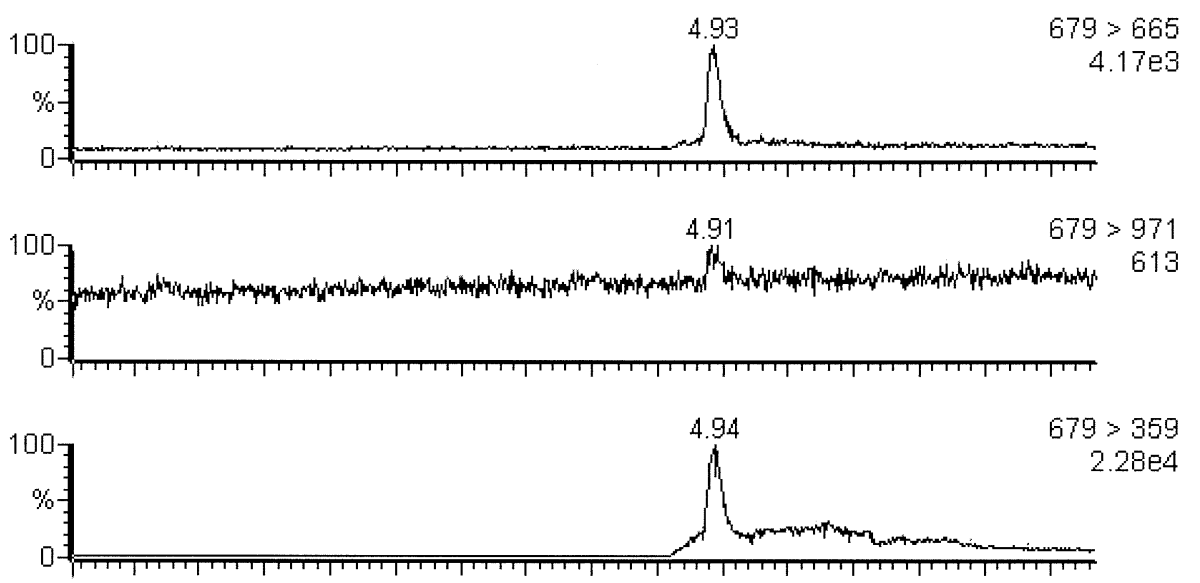

Figure 3. Reconstructed ion chromatograms of an MRM analysis of ethyl cobalamin in a transalkylation reaction mixture.

12.6-16.2 min. The reconstructed ion chromatogram of all ten ethyl PTEs are shown in Figure 6 and the full scan spectrum of the retention time interval where the ethyl PTEs were eluted is shown in Figure 7.

The areas for each ethyl PTE in the large-volume injection experiments were plotted against the injection volume in order to roughly show the capacity of the pre-column to retain the analytes (Figure 8). A nonincrease in response would support overloading of the pre-column.

Fragmentation pattern. For confirmation of the structures product-ion spectra were recorded. Using the large-volume injections and a flow-rate of $4 \mu \mathrm{L} / \mathrm{min}$ over the analytical column, product-ion spectra (CV 20 $\mathrm{V}, \mathrm{CE} 16$ and $17 \mathrm{eV}$ ) of all ten ethyl PTEs were obtained. The large volumes injected and the lower flow-rates increased the signal to noise ratio of the spectra. Compared to the methyl PTE standard, the fragments of all analytes indicated an ethyl PTE structure.

From the product-ion spectra similar fragmentation patterns for the ethyl PTEs can be seen (Figure 9). Structures for the major (typical) product ions are proposed in Figure 10. All ethyl PTEs gave rise to $\left[\mathrm{BH}_{2}\right]^{+}$fragments of both bases as a result of cleavage of the glycosidic bond, but to different extent depending
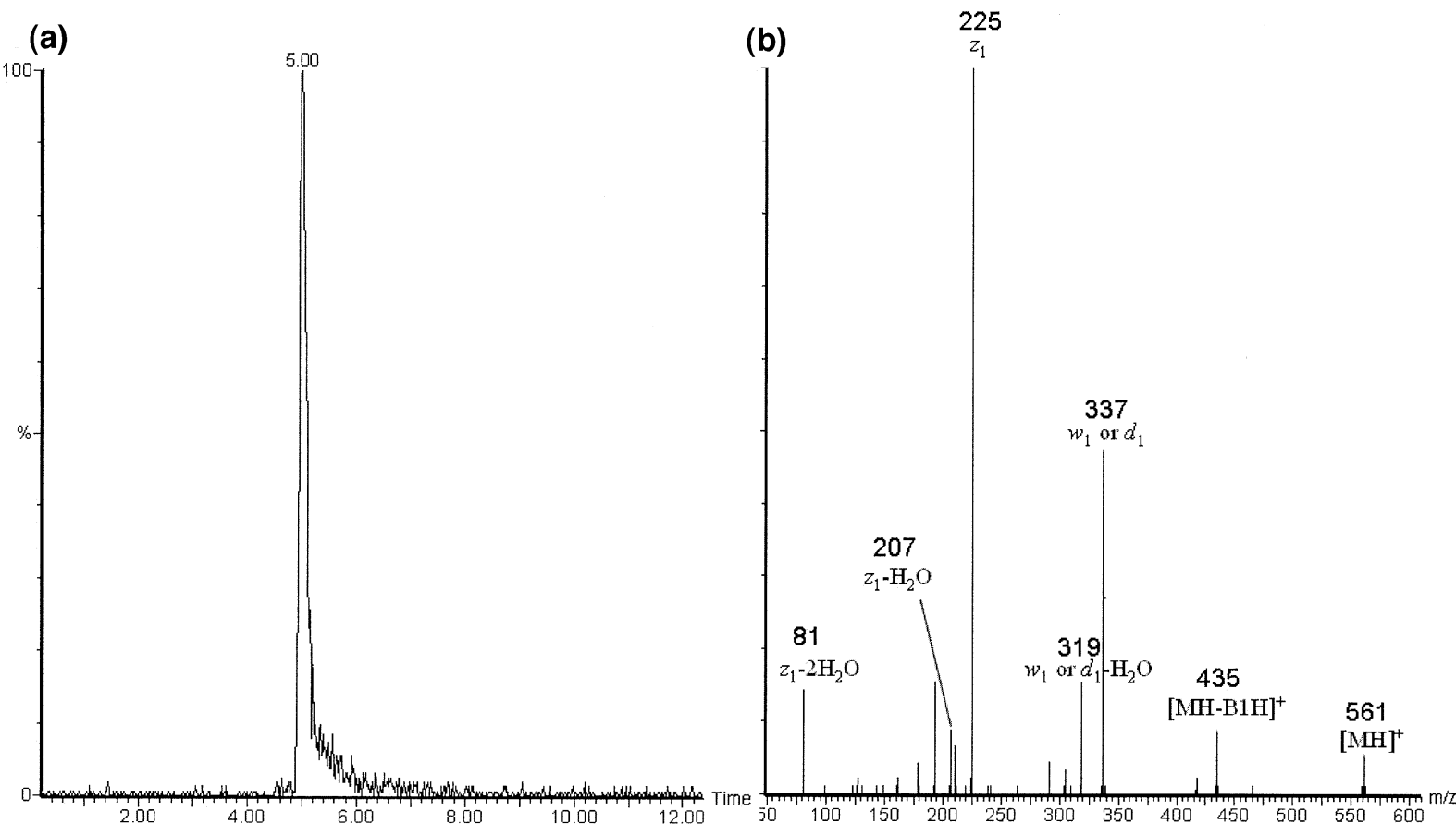

Figure 4. Product ion scan of the $[\mathrm{M}+\mathrm{H}]^{+}$of the TpMeT standard. Ion chromatogram (a) and the product ion spectrum (b). Cone voltage $20 \mathrm{~V}$ and collision energy $15 \mathrm{eV}$ (Q-Tof 2 instrument). 


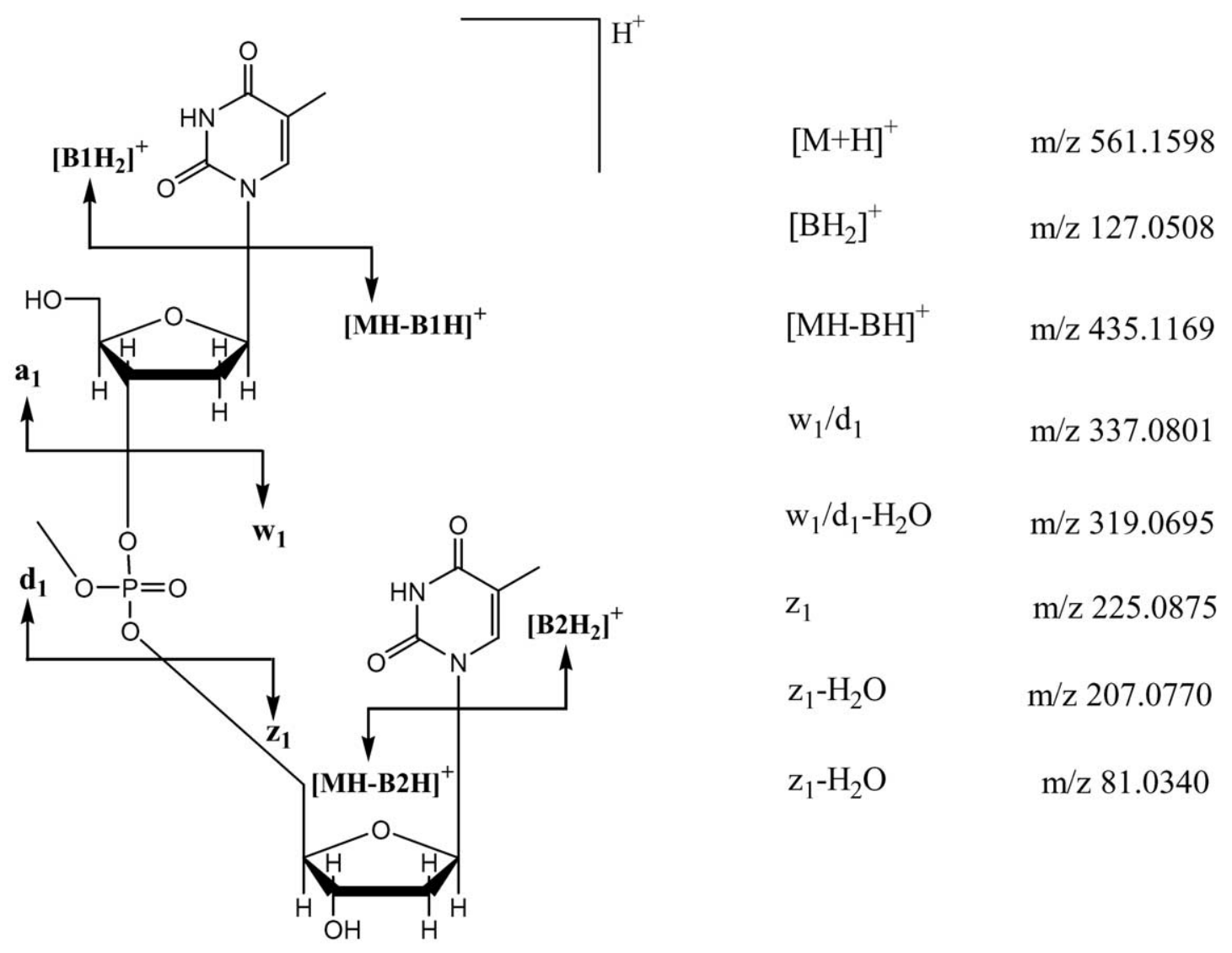

Figure 5. Fragmentation pattern of the methyl phopshotriester with fragmentation nomenclature of McLuckey et al. [21].

on the type of the bases. The thymine base is hardly detected as $\left[\mathrm{BH}_{2}\right]^{+}$, a result in agreement with earlier experience of (oligo)nucleotide fragmentation patterns [21]. In addition, fragments as a result of the loss of $\mathrm{BH}$ were detected for all ethyl PTEs except for those containing thymine, where loss of $\mathrm{BH}$ was hardly seen. This indicates that cleavage of the glycosidic bond between deoxyribose and thymine is not as favored as for the other three bases where the $\left[\mathrm{BH}_{2}\right]^{+}$fragments are major. Phosphate-alkylated-mononucleotides were also major fragments ( $w_{1}$ and $d_{1}$ ions) as a result of cleavage of the $3^{\prime}$ - and $5^{\prime}$-phosphodiester bond, respectively. Typical fragments observed for the respective ethyl PTE are summarized in Table 2.

In order to add more evidence to the structures the cone voltage was raised to $45 \mathrm{~V}$ to produce some in-source fragmentation for an ethyl PTE, followed by a product-ion scan. The ethyl-containing fragments $\mathrm{m} / \mathrm{z}$
336 and $360\left(w_{1}\right.$ and $d_{1}$ of $\mathrm{dApEtdC}$ and $\left.\mathrm{dCpEtdA}\right)$ being the same fragment but with different bases, were chosen as precursors and the only product ion formed for both ions was their respective $\left[\mathrm{BH}_{2}\right]^{+}$fragment, indicating no base alkylation.

The ethyl PTE, TpEtT, showed to a large extent fragment $\mathrm{m} / \mathrm{z} 225$ similarly to the methyl PTE standard, TpMeT. After elucidation we suggest a thymidinespecific structure which after loss of water leads to $\mathrm{m} / \mathrm{z}$ 207, a fragment also seen for these PTEs but at a lower abundance. However, $\mathrm{m} / \mathrm{z} 207$ was indicated also in non-thymine containing ethyl PTEs, sometimes together with $\mathrm{m} / \mathrm{z} 225$ and both at relatively low abundances. By accurate mass measurements it was concluded that there are both thymine-specific fragments and alkyl-specific fragments at $\mathrm{m} / \mathrm{z} 225.0875 / 207.0770$ and $m / z 225.0528 / 207.0422$, respectively (Figure 11). To further confirm this, the alkyl-specific fragments $\mathrm{m} / \mathrm{z}$

Table 1. The ten different combinations of ethyl phosphotriester configurations and their $[\mathrm{M}+\mathrm{H}]^{+}$masses

\begin{tabular}{llll}
\hline PTE & {$[\mathrm{M}+\mathrm{H}]^{+}$} & \multicolumn{1}{c}{ PTE } & {$[\mathrm{M}+\mathrm{H}]^{+}$} \\
\hline \hline dApEtdA & 593.1986 & dApEtdC or dCpEtdA & 569.1873 \\
dGpEtdG & 625.1884 & dApEtT or TpEtdA & 584.1870 \\
TpEtT & 575.1754 & dGpEtdC or dCpEtdG & 585.1823 \\
dCpEtdC & 545.1761 & dGpEtT or TpEtdG & 600.1819 \\
dApEtdG or dGpEtdA & 609.1935 & TpEtdC or dCpEtT & 560.1758 \\
\hline
\end{tabular}




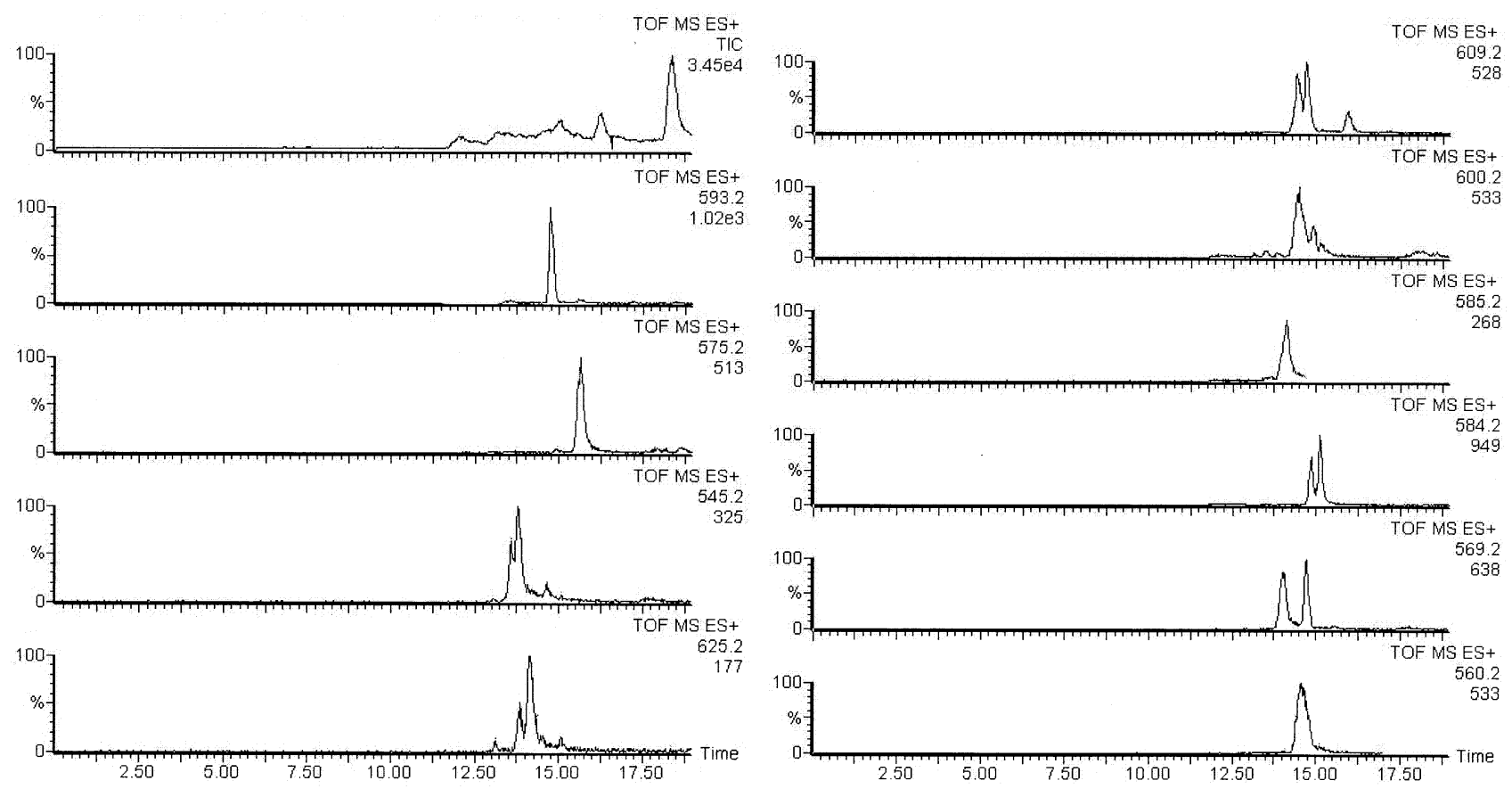

Figure 6. Full scan analysis of enzymatic hydrolysate of calf thymus DNA treated in vitro with $N$-ethyl- $N$-nitrosourea $(200 \mu \mathrm{L})$. Total and reconstructed ion chromatograms for ten ethyl PTE.

225.0528 and 207.0422 should be present in the production spectrum of the methyl PTE standard but at 14 masses lower, i.e., $\mathrm{m} / \mathrm{z} 211.0372$ and 193.0266. The fragment $m / z 193$ is present and confirmed by accurate mass measurement, whereas 211 is not seen, but that is

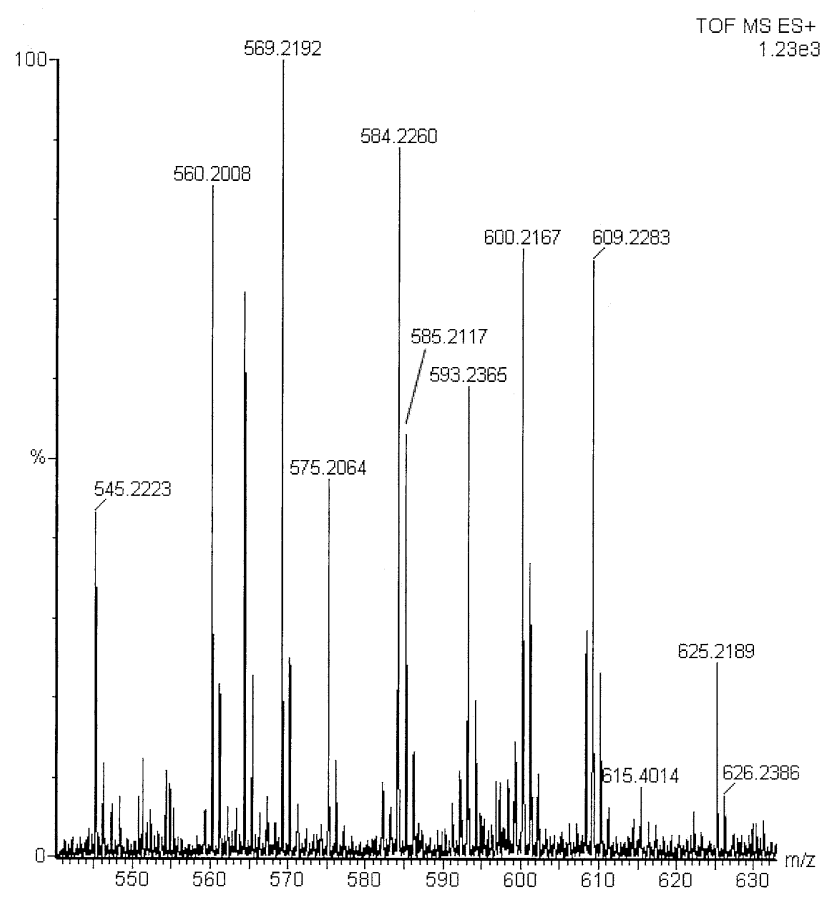

Figure 7. Summed full scan spectrum taken over the time range where the ethyl PTEs are eluted. in agreement with the hardly seen alkyl-specific fragment $m / z 225.0528$ for ethyl PTEs.

The $m / z 81$ fragment is a deoxyribose moiety that lost $2 \mathrm{H}_{2} \mathrm{O}$ and is present for all ethyl PTEs. The formation is suggested to occur via several pathways (cf. Figure 11).

Since the ester bonds ( 3 ' in our study) to be cleaved by the enzymes are resistant to the enzymes (Nuclease

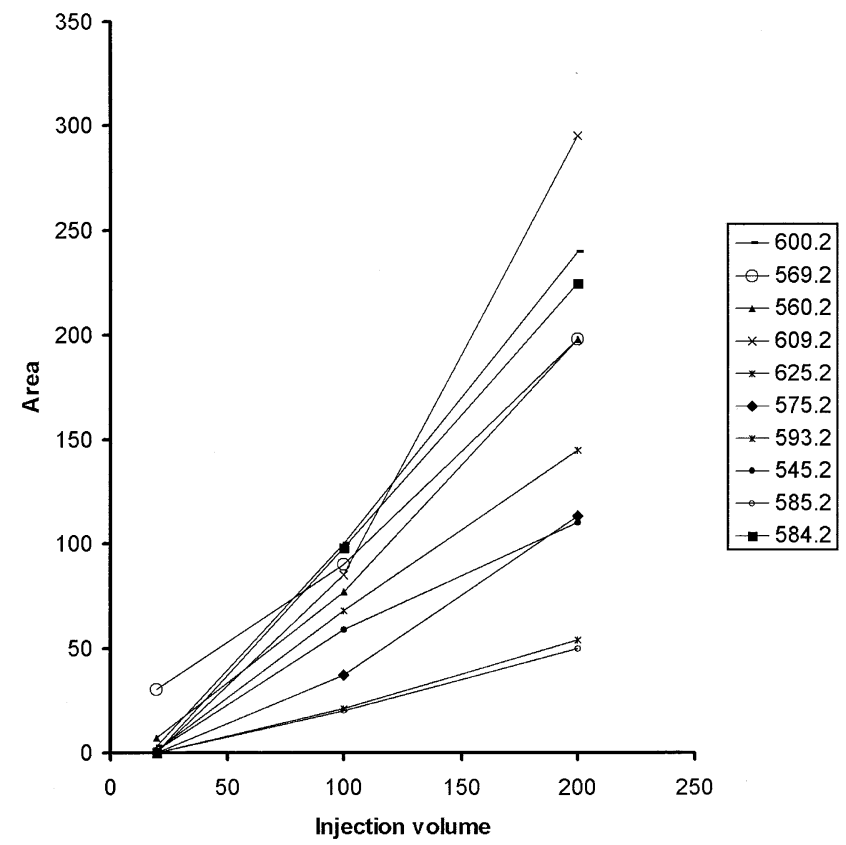

Figure 8. The area of the masses in RIC plotted against the injection volumes. 

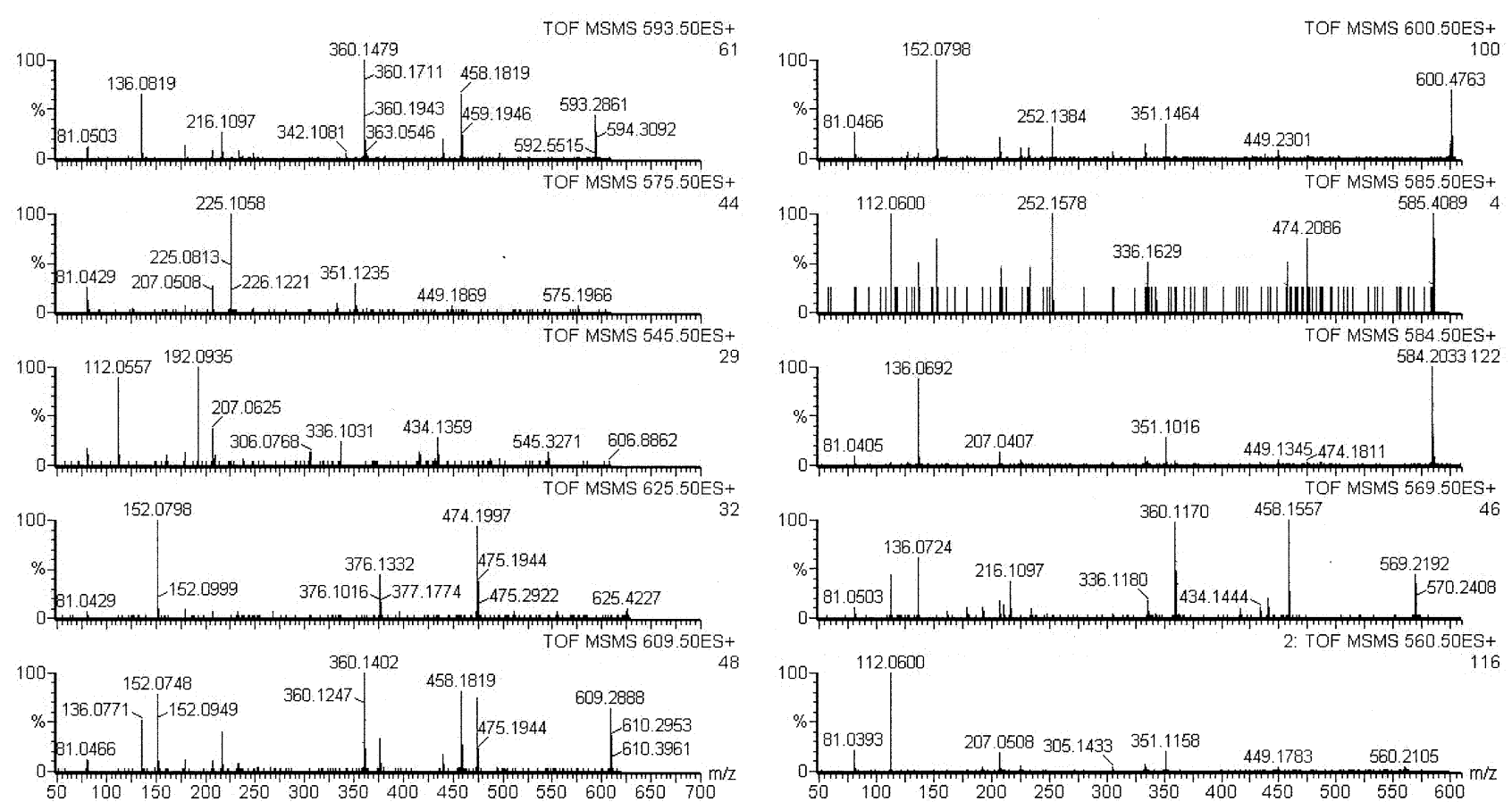

Figure 9. The product-ion spectrum of each ethyl PTE found in ENU-treated calf thymus DNA hydrolysate. Injection volume $=200 \mu \mathrm{L} . \mathrm{CV}=20 \mathrm{~V}, \mathrm{CE}=17 \mathrm{eV}(15 \mathrm{eV}$ for $\mathrm{m} / z 625.5$ and 575.5).

P1 and snake venom phosphodiesterase) due to esterification of the phosphate oxygen, the alkyl PTE formation is expected when nucleases are combined with alkaline phosphatase (Figure 1) (nucleases only would lead to a phosphate-alkylated dinucleotide). This feature together with the results of the product-ion spectra (masses of the precursors, the non-alkylated base fragments, phosphate-alkylated-mononucleotides, in source fragmentation experiments) support the PTE configuration. The resistance of the inter-nucleotide bond in a completely esterified phosphate group (alkylated phosphate oxygen) has not been investigated for all alkyl groups. However, since the nucleases are diester hydrolase's being diester-bond specific the alkyl PTE products would generally be expected after enzymatic hydrolysis.

In earlier studies by Deforce et al. [22] where nucleotides has been treated in vitro, phosphate-alkylated dAMP has been shown together with base-alkylated dAMP, where the differentiation is based on the formation of the non-alkylated base fragment $\left([\mathrm{B}-2 \mathrm{H}]^{2-}\right.$ in negative ionization mode of ESI) and the phosphatealkylated 2'-deoxyribofuranosyl moiety for the phosphate-alkylated dAMP. However, in some publications where DNA, treated in vitro in combination with enzymatic degradation into nucleotides and nucleosides, has been analyzed, it is often stated that phosphate alkylations were not formed due to the lack of phosphatealkylated nucleotides. If the resistance of the enzymes is the same regardless of alkyl group then the proper product to search for would be a phosphate-alkylated dinucleotide if degraded into nucleotides, and phosphotriesters if degraded into nucleosides.

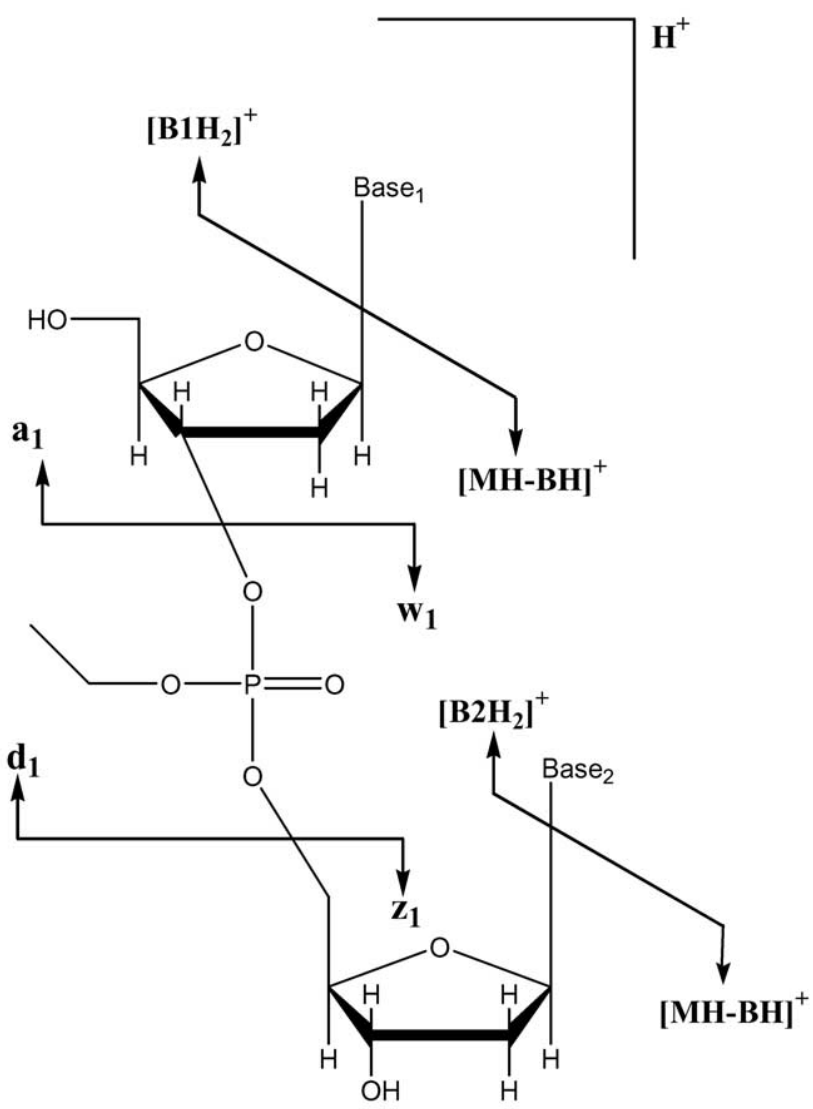

Figure 10. Structure of an ethyl PTE illustrating tentative fragmentation in ESI-MS/MS. The $a_{1} / w_{1}$ and $b_{1} / z_{1}$ ions refers to the McLuckey fragmentation nomenclature for oligonucleotides [21]. 
Table 2. Summary of the typical fragments seen in the product ion spectrum of each ethyl PTE

\begin{tabular}{|c|c|c|c|c|c|c|c|c|c|c|c|c|c|}
\hline \multirow[b]{2}{*}{ Ethyl-PTE } & \multirow[b]{2}{*}[\mathrm{M}+\mathrm{H}]{$^{+}$} & \multicolumn{4}{|c|}{$\left[\mathrm{BH}_{2}\right]^{+}$} & \multicolumn{4}{|c|}{$[\mathrm{MH}-\mathrm{B} 1 \mathrm{H}]^{+}$or $[\mathrm{MH}-\mathrm{B} 2 \mathrm{H}]^{+}$} & \multicolumn{4}{|c|}{$\mathrm{w}_{1} / \mathrm{d}_{1}$} \\
\hline & & G & A & $\mathrm{C}$ & $\mathrm{T}$ & G & A & $\mathrm{C}$ & $\mathrm{T}$ & G & A & $\mathrm{C}$ & $\mathrm{T}$ \\
\hline dGpEtdG & 625 & 152 & & & & 376 & & & & 474 & & & \\
\hline dApEtdA & 593 & & 136 & & & & 360 & & & & 458 & & \\
\hline $\mathrm{dCpEtdC}$ & 545 & & & 112 & & & & 336 & & & & 434 & \\
\hline TpEtT & 575 & & & & 127 & & & & 351 & & & & 449 \\
\hline dGpEtT or TpEtdG & 600 & 152 & & & $127^{*}$ & & & 351 & 474 & & & 449 & \\
\hline $\mathrm{dGpEtdC}$ or $\mathrm{dCpEtdG}$ & 585 & 152 & & 112 & & & & 336 & & 474 & & 434 & \\
\hline $\mathrm{dGpEtdA}$ or dApEtdG & 609 & 152 & 136 & & & 376 & 360 & & & 474 & 458 & & \\
\hline $\mathrm{dApEtdC}$ or $\mathrm{dCpEtdA}$ & 569 & & 136 & 112 & & & 360 & 336 & & & 458 & 434 & \\
\hline dApEtT or TpEtdA & 584 & & 136 & & $127^{*}$ & & $360^{*}$ & & 351 & & & & 449 \\
\hline TpEtdC or dCpEtT & 560 & & & 112 & $127^{*}$ & & & nd & 351 & & & & 449 \\
\hline
\end{tabular}

*Relatively low abundance.

\section{Accurate Mass Measurement}

The methyl PTE standard. Elemental composition of the fragments observed in the MS/MS experiment of the methyl PTE (TpMeT) was determined using the precursor ion $([\mathrm{M}+\mathrm{H}]+; m / z 561)$ of TpMeT as lock-mass. The methyl standard was injected via syringe infusion and MS/MS data was acquired at a varying cone voltage varying from 20 to $30 \mathrm{~V}$ and a collision energy varying from 15 to $20 \mathrm{eV}$. Accurate mass measurements were obtained within $5 \mathrm{ppm}$ for four of the six major fragments (Table 3) using the precursor ion as lock mass. The accurate mass for $m / z 81$ was obtained with $1.0 \mathrm{mD}$ mass difference, though giving high relative error due to the low mass. The use of a fragment ion instead of a precursor ion as lock mass decreased the mass difference to $0.1 \mathrm{mDa}$ with a relative error of $1.2 \mathrm{ppm}$.

Ethyl PTEs in ENU-treated DNA. The elemental compositions of the different precursors and the different product ions of the ethyl PTEs found in ENU-treated DNA were also determined by accurate mass measurements. The signal to noise ratios in the product-ion spectra of 20 and even $100 \mu \mathrm{L}$ injections were too low. In order to obtain accurate mass measurements, $200 \mu \mathrm{L}$

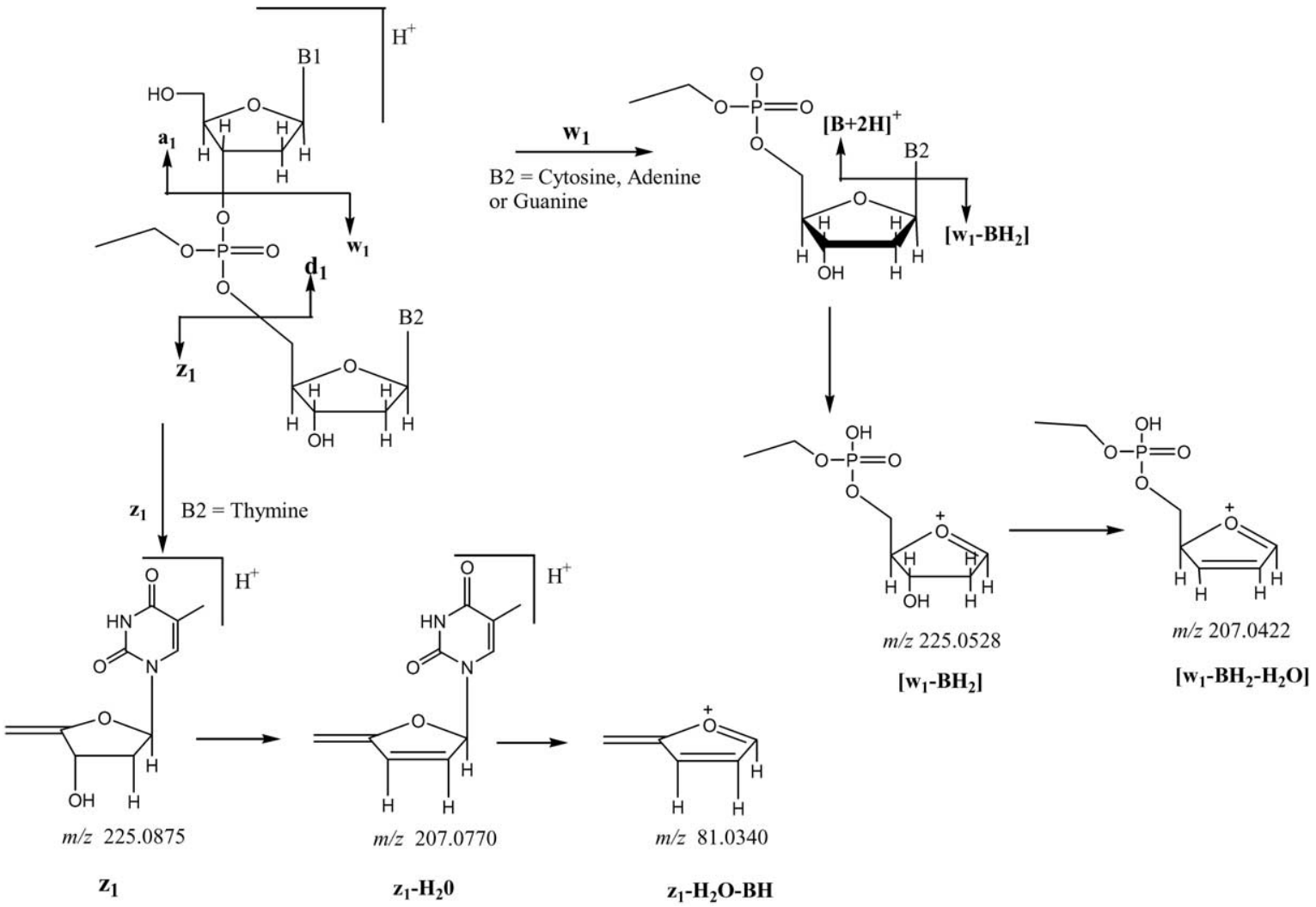

Figure 11. Tentative fragmentation leading to thymine-specific and alkyl-specific fragments $\mathrm{m} / \mathrm{z} 225$, $m / z$ 207, and $m / z 81$ for the ethyl PTEs. 
Table 3. Accurate mass measurement of the product ions of the methyl PTE standard

\begin{tabular}{lcccc}
\hline $\begin{array}{l}\text { Product ions of } \\
\text { TpMeT }\end{array}$ & Theoretical mass & Experimental mass & $\mathrm{mDa}$ & \\
\hline \hline$[\mathrm{M}+\mathrm{H}]^{+}$ & 561.1985 & Lock-mass & & $\mathrm{p}$ \\
{$[\mathrm{MH}-\mathrm{BH}]^{+}$} & 435.1169 & 435.1167 & -0.2 & -0.4 \\
{$\left[\mathrm{~d}_{1}\right]^{+} /\left[\mathrm{w}_{1}\right]^{+}$} & 337.0801 & 337.0793 & -0.8 & -2.3 \\
$\left.\left[\mathrm{w}_{1}-\mathrm{BH}\right]_{2}\right]^{+}$ & 193.0266 & 193.0260 & $-2.4 /-0.6^{*}$ & $-12.5 /-3.0^{*}$ \\
{$\left[\mathrm{z}_{1}-\mathrm{H}_{2} \mathrm{O}\right]^{+}$} & 207.0770 & 227.0777 & 0.7 & 3.5 \\
{$\left[\mathrm{z}_{1}-\mathrm{H}_{2} \mathrm{O}-\mathrm{BH}\right]^{+}$} & 81.0340 & 81.0350 & $1.0 / 0.1^{*}$ & $11.8 / 1.2^{*}$ \\
\hline
\end{tabular}

*Using 337.0801 as lock mass.

injections were used. The flow-rate was $4 \mu \mathrm{L} / \mathrm{min}$ over the analytical column. The standard (TpMeT) was used as a lock mass. The obtained experimental masses were within 5 ppm for 9 of the 10 ethyl PTE (Table 4). The respective precursor masses were used as a lock-mass for the different product ion spectra. Accurate masses within a relative error of 5 ppm was not obtained for all product ions due to low abundance.

\section{Isomerism}

The gradient used initially (linear increase of 5.3\% $\mathrm{B} / \mathrm{min}$ ) led mainly to single chromatographic peaks for every ethyl PTE. The six ethyl PTEs that have different bases are expected to occur in two forms (constitutional isomers) depending on the site of the base in relation to the $3^{\prime}$ - or $5^{\prime}$-deoxyribose. A slower gradient was tested (linear increase to $2.5 \% \mathrm{~B} / \mathrm{min}$ ). Using the new gradient and the lower flow-rate of $4 \mu \mathrm{L} /$ min over the analytical column more or less all ethyl PTEs with different bases did now appear as double peaks. However, some of the ethyl PTEs containing the same bases also eluted as double peaks using the slower gradient (Figure 13). This observation could be explained by the fact that the ethyl PTEs with the same bases are also isomers (diastereoisomers; epimers) due to the chiral center at the phosphorus atom after alkylation. The assumption that the ethyl PTEs with different bases would give 4 peaks can not be demonstrated but might be explained by the capacity of the column and system being too low.

The product-ion spectrum of the two peaks of an ethyl PTE is not expected to differ in pattern with regard to the fragment masses (Figure 12). One could expect a difference in intensity of the particular fragments as a result of the influence of the type of the base

Table 4. Accurate mass measurements of the molecular ions $[\mathrm{M}+\mathrm{H}]^{+}$and fragment ions that were presented to be formed according to Figure 6

\begin{tabular}{|c|c|c|c|c|}
\hline Precursors & $\begin{array}{c}\text { Theoretical } \\
\text { mass }\end{array}$ & $\begin{array}{l}\text { Experimental } \\
\text { mass }\end{array}$ & $\mathrm{D}(\mathrm{mDa})$ & $D(p p m)$ \\
\hline$[\mathrm{dApFtdA}+\mathrm{H}]^{+}$ & 593.1986 & 593.1974 & -1.2 & -2.0 \\
\hline$[\mathrm{dGpEtdG}+\mathrm{H}]^{+}$ & 625.1884 & nd & - & - \\
\hline$[\mathrm{TdEtT}+\mathrm{H}]^{+}$ & 575.1754 & 575.1768 & 1.4 & 2.4 \\
\hline$[\mathrm{dCpEtdC}+\mathrm{H}]^{+}$ & 545.1761 & 545.1744 & -1.7 & -3.1 \\
\hline$[\mathrm{dApEtdG}+\mathrm{H}]^{+}$ & 609.1935 & 609.1965 & 3.0 & 4.9 \\
\hline$[\mathrm{dApEtT}+\mathrm{H}]^{+}$ & 584.1870 & 584.1849 & -2.1 & -3.6 \\
\hline$[\mathrm{dApEtdC}+\mathrm{H}]^{+}$ & 569.1873 & 569.1871 & -0.2 & -0.4 \\
\hline$[\mathrm{dGpEtT}+\mathrm{H}]^{+}$ & 600.1819 & 600.1799 & -2.0 & -3.4 \\
\hline$[\mathrm{dGpEtdC}+\mathrm{H}]^{+}$ & 585.1823 & 585.1840 & 1.7 & 3.0 \\
\hline$[\mathrm{TpEtdC}+\mathrm{H}]^{+}$ & 560.1758 & 560.1760 & 0.2 & 0.4 \\
\hline Product-ions & Theoretical & Experimental & $\mathrm{D}(\mathrm{mDa})$ & $\mathrm{D}(\mathrm{ppm})$ \\
\hline$\overline{\left.\mathrm{AH}_{2}\right]^{+}}$ & 136.0623 & 136.0622 & -0.1 & -0.9 \\
\hline$\left[\mathrm{GH}_{2}\right]^{+}$ & 152.0572 & 152.0592 & 2.0 & 12.9 \\
\hline$\left[\mathrm{TH}_{2}\right]^{+}$ & 127.0508 & $n d$ & - & - \\
\hline$\left[\mathrm{CH}_{2}\right]^{+}$ & 112.0511 & $112.0536^{*}$ & 2.4 & 21.5 \\
\hline$\left[\mathrm{M}-\mathrm{BH}_{2}\right]^{+}($Base $=$Adenine $)$ & 458.1441 & 458.1451 & 1.0 & 2.2 \\
\hline$\left[\mathrm{M}-\mathrm{BH}_{2}\right]^{+}($Base $=$Guanine $)$ & 474.1390 & 474.1328 & 4.1 & 8.7 \\
\hline$\left[\mathrm{M}-\mathrm{BH}_{2}\right]^{+}($Base $=$Thymine $)$ & 449.1325 & $n d$ & - & - \\
\hline$\left[\mathrm{M}-\mathrm{BH}_{2}\right]^{+}($Base $=$Cytidine $)$ & 434.1328 & 434.1342 & 1.4 & 3.1 \\
\hline$\left[\mathrm{d}_{1}\right]^{+} /\left[\mathrm{w}_{1}\right]^{+}($Base $=$Adenine $)$ & 360.1073 & 360.1072 & -0.1 & -0.3 \\
\hline$\left[d_{1}\right]^{+} /\left[w_{1}\right]^{+}($Base $=$Guanine $)$ & 376.1022 & 376.0988 & -3.4 & -9.1 \\
\hline$\left[d_{1}\right]^{+} /\left[w_{1}\right]^{+}($Base $=$Thymine $)$ & 351.0957 & 351.0964 & 0.7 & 1.9 \\
\hline$\left[d_{1}\right]^{+} /\left[w_{1}\right]^{+}$(Base $=$Cytidine $)$ & 336.0961 & $n d$ & - & - \\
\hline
\end{tabular}

nd Too low abundance to be detected. 
a)

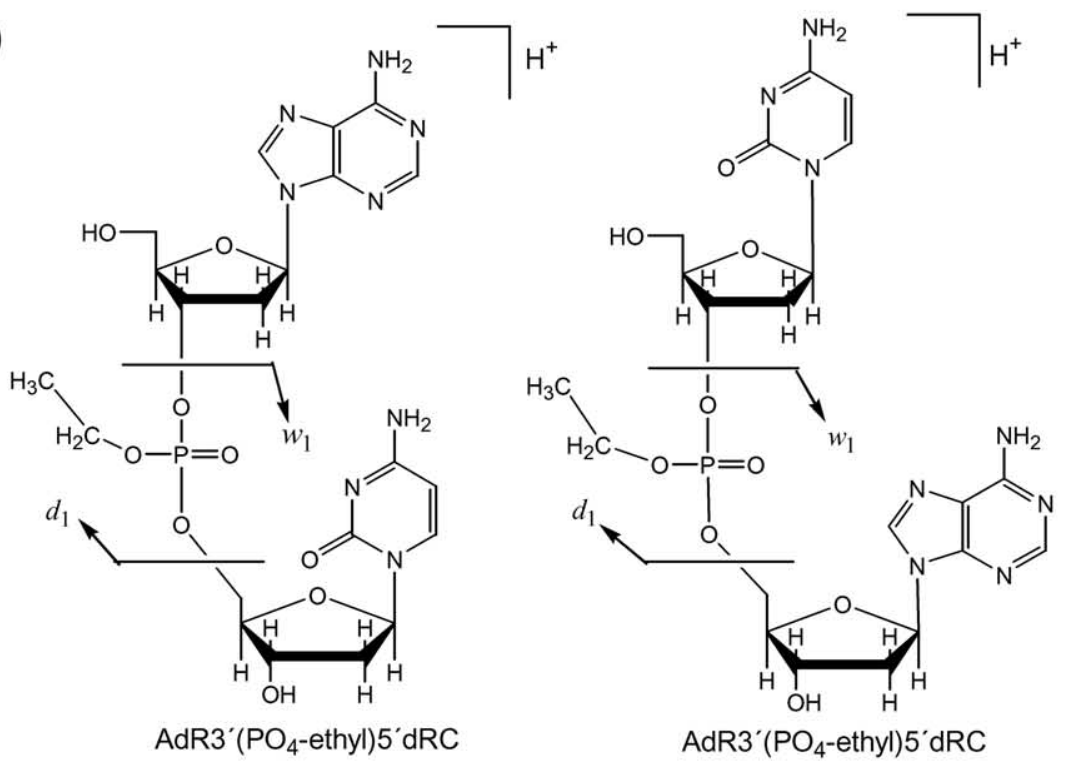

b)

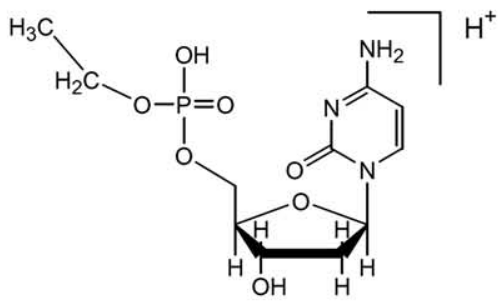

$\mathrm{m} / \mathrm{z} 336$

$w_{1}$ fragments

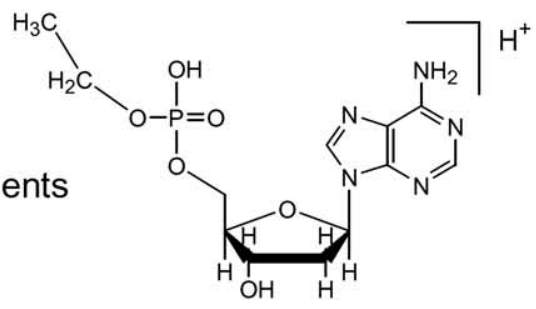

$\mathrm{m} / \mathrm{z} 360$

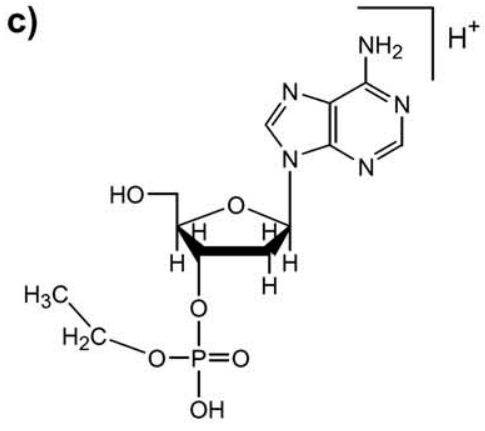

$\mathrm{m} / \mathrm{z} 360$

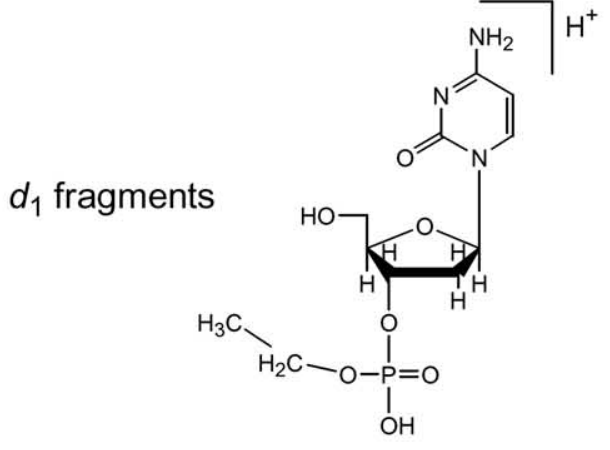

$\mathrm{m} / \mathrm{z} 336$

Figure 12. Illustration of the formation of isomeric fragments of an ethyl PTE with different bases.

and its position to the $3^{\prime}$ - and $5^{\prime}$-diester bonds. The product-ion spectrum in peak one was the same as that of peak two, except for indications of changes in intensity of the base-specific fragments (Figure 14). For further elucidation of isomeric forms additional work has to be performed. The detection and structural elucidation of the ethyl PTEs was the major aim in this study.

\section{Limit of detection and adduct level}

For comparison of the mass spectrometric behavior between an alkylcobalamin and a corresponding alkyl PTE, methyl cobalamin and methyl PTE were used. This was performed on the Quattro II triple quadropole mass spectrometer in MRM mode. The limit of detection of methylcobalamin (Me-Cbl; channel $673>655$ ) 

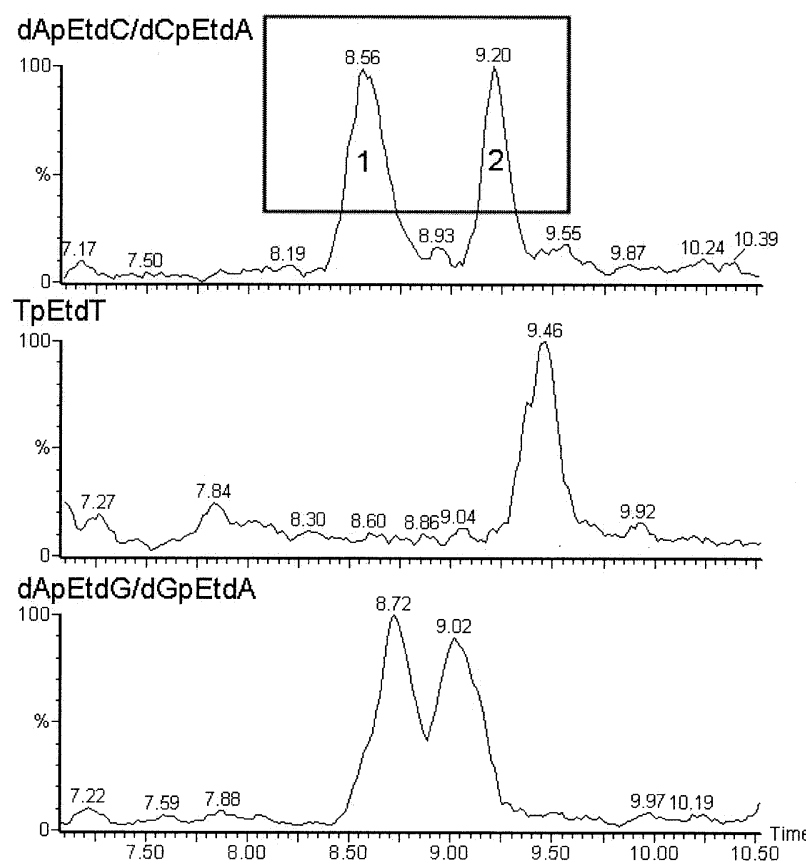

Figure 13. Some examples of the chromatography of three ethyl PTEs.

and a methyl PTE (TpMeT; channel $561>225)$ was 2 fmol $\left(20 \mu \mathrm{L} ; 10^{-10} \mathrm{M}\right)$ and 5 fmol $\left(5 \mu \mathrm{L} ; 10^{-9} \mathrm{M}\right)$, respectively, at a signal to noise of 4 .

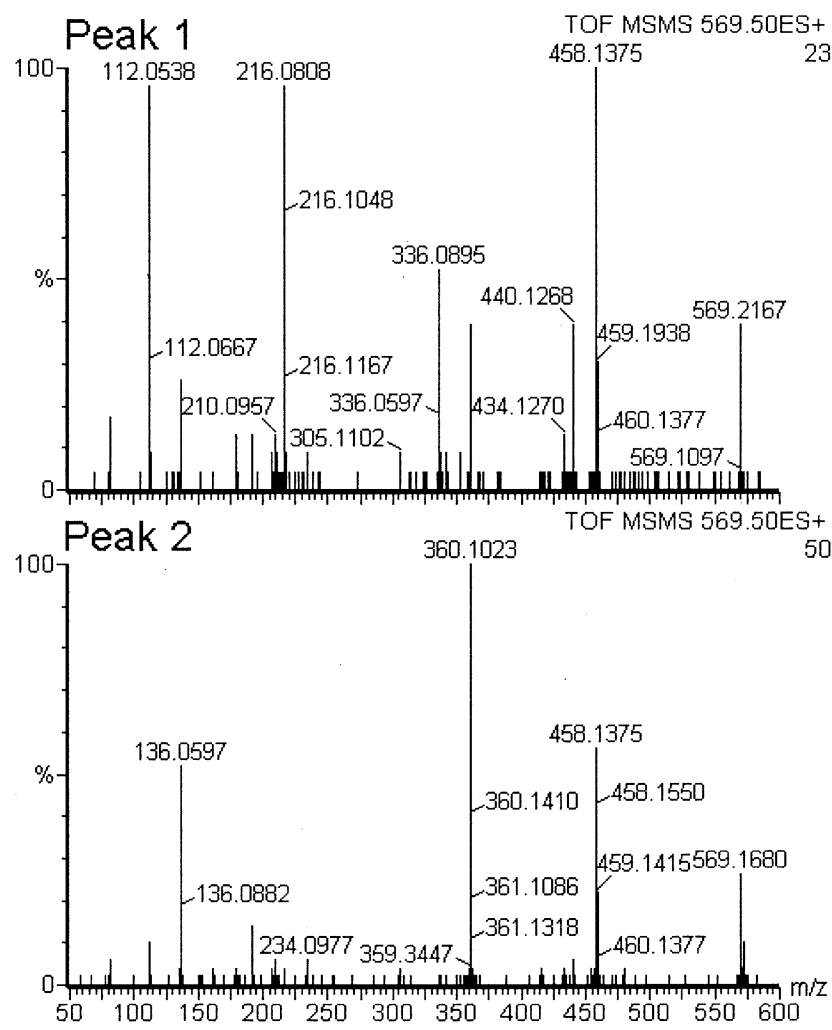

Figure 14. The product-ion spectrum of Peaks 1 and 2, respectively, of the ethyl PTE dApEtdC/dCpEtdA shown in Figure 13.
Quantitative work has not been carried out, but in order to get an idea about the level of ethyl PTEs measured in ENU-treated DNA, product ion scan (CV $=20 \mathrm{~V}, \mathrm{CE}=16 \mathrm{eV}$ ) on the Q-Tof 2 instrument of the TpMeT standard was compared with the most similar ethyl PTE, TpEtT, in the hydrolysate of ENU-treated DNA. Comparing the areas under the peaks the level of TpEtT in ENU-treated DNA amounted to pmol level/ $100 \mu \mathrm{g}$ DNA. Roughly speaking this implies a TpEtT adduct level around 1 adduct per $10^{4}$ normal nucleotides, which is approx. $1 / 10$ of all ethyl PTEs.

\section{Conclusion}

To the best of our knowledge it is the first time phosphotriester configurations in DNA have been characterized by means of LC-ESI-MS/MS. Simultaneously, the corresponding alkyl-cobalamin was measured after transalkylation of an identical DNA hydrolysate. Although quantitative LC-MS has not been performed the alkyl-cobalamin level was found to be compatible with the sum of ethyl PTEs. The two approaches show different advantages. The use of alkyl-cobalamins as measures of DNA-phosphate adducts is preferrable for quantitative work, whereas using PTEs the signal is spread over ten different analytes. Applying the transalkylation method all PTEs are gathered into one analyte, a major advantage in the hunt for sufficiently high sensitivity. Furthermore, every new compound to be studied requires ten different products to be characterized and quantified using isotope-substituted standards. On the other hand the analysis of individual PTEs will give qualitative information and can be used for validation of the transalkylation method. Conclusively, two complementary approaches are available for the analysis of DNA-phosphate adducts, useful for different purposes.

\section{Acknowledgments}

The authors thank Professor Margareta Törnqvist for important contributions, Mr Robin Tuytten and Mr. Bart Van den Driessche for valuable discussions, and Professor Lars Ehrenberg for critical reading. This work was financially supported by a RAFO-BOF grant, The Swedish Research Council for Environment, Agricultural Sciences and Spatial Planning, and by EU grant HPRN-CT2002-00195

\section{References}

1. Miller, E. C. and Miller, J. A. Mechanisms of chemical carcinogenesis: Nature of proximate carcinogens and interactions with macromolecules. Pharmacol. Rev. 1966, 18, 805-838.

2. Brookes, P.; Lawley, P. D. Alkylating Agents. Br. Med. Bull. 1964, 20, 91-95.

3. Hussain, S.; Ehrenberg, L. Prophage inductive efficiency of alkylating agents and radiations. Int. J. Radiat. Biol. Relat. Stud. Phys. Chem. Med. 1975, 27, 355-362.

4. Loveless, A. Possible Evidence of $\mathrm{O}^{6}$ Alkylation of Deoxyguanosine to the Mutagenicity and Carcinogenicity of Nitrosamines and Nitrosamides. Nature 1969, 223, 206. 
5. den Engelse, L.; Menkveld, G. J.; De Brij, R. J.; Tates, A. D. Formation and stability of alkylated pyrimidines and purines (including imidazole ring-opened 7-alkylguanine) and alkylphosphotriesters in liver DNA of adult rats treated with ethylnitrosourea or dimethylnitrosamine. Carcinogenesis 1986, 7, 393-403.

6. den Engelse, L.; De Graaf, A.; De Brij, R. J.; Menkveld, G. J. O²and $\mathrm{O}^{4}$-ethylthymine and the ethylphosphotriester $\mathrm{dTp}(\mathrm{Et}) \mathrm{dT}$ are highly persistent DNA modifications in slowly dividing tissues of the ethylnitrosourea-treated rat. Carcinogenesis 1987, 751, 751-757.

7. Törnqvist, M.; Fred, C.; Haglund, J.; Helleberg, H.; Paulsson, B.; Rydberg, P. Protein Adducts: Quantitative and Qualitative Aspects of Formation, Analysis, and Applications. J. Chromatogr. B Anal. Technol. Biomed. Life Sci. 2002, 778, 279-308.

8. Ross, W. C. J. Biological Alkylating Agents; Butterworths: London, 1962, p 83.

9. Walles, S.; Ehrenberg, L. Effects of $\beta$-hydroxyethylation and $\beta$-methoxyethylation on DNA in vitro. Acta Chem. Scand. 1968, 22, 2727-2729.

10. Miller, P. S.; Fang, K. N.; Kondo, N. S.; Ts'o, P. O. Syntheses and Properties of Adenine and Thymine Nucleoside Alkyl Phosphotriesters, the Neutral Analogs of Dinucleoside Monophosphates. J. Am. Chem. Soc. 1971, 93, 6657-6665.

11. Swenson, D. H.; Lawley, P. D. Alkylation of deoxyribonucleic acid by carcinogens dimethyl sulphate, ethyl methanesulphonate $N$-ethyl- $N$-nitrosourea and $N$-methyl- $N$-nitrosourea. Relative reactivity of the phosphodiester site thymidylyl(3'5')thymidine. Biochem. J. 1978, 171, 575-587.

12. Saris, C. P.; Damman, S. J.; van den Ende, A. M.; Westra, J. G.; den Engelse, L. A. ${ }^{32} \mathrm{P}$-postlabeling assay for the detection of alkylphosphotriesters in DNA. Carcinogenesis 1995, 16, 1543-1548.

13. Singh, R.; Sweetman, G. M.; Farmer, P. B.; Shuker, D. E.; Rich, K. J. Detection and characterization of two major ethylated deoxyguanosine adducts by high performance liquid chromatography, electrospray mass spectrometry, and ${ }^{32} \mathrm{P}$-postlabeling. Development of an approach for detection of phosphotriesters. Chem. Res. Toxicol. 1997, 10, 70-77.

14. Esmans, E. L.; Broes, D.; Hoes, I.; Lemière, F.; Vanhoutte, K. Liquid Chromatography-Mass Spectrometry in Nucleoside,
Nucleotide, and Modified Nucleotide Characterization. J. Chromatogr. A 1998, 794, 109-127.

15. Esmans, E. L. Coupling of liquid chromatography to mass spectrometry: twenty-five years of exiting developments. In Fundamentals and Applications of Gas Phase Ion Chemistry; K. R. Jennings, Ed. From the NATO ASI Series C: Mathematical and Physical Sciences, Vol. 521, published in cooperation with the NATO Scientific Affairs Division. Kluwer Academic Publishers: Dordrecht/Boston/London, 1999, pp 115-147.

16. Embrechts, J.; Lemière, F.; Van Dongen, W.; Esmans, E. L.; Buytaert, P.; Van Marck, E.; Kockx, M.; Makar, A. Detection of estrogen DNA-adducts in human breast tumor tissue and healthy tissue by combined nano LC-nano ES tandem mass spectrometry. J. Am. Soc. Mass Spectrom. 2003, 14, 482-491.

17. Haglund, J.; Rafiq, A.; Ehrenberg, L.; Golding, B. T.; Törnqvist, M. Transalkylation of Phosphotriesters Using Cob(I)Alamin: Toward Specific Determination of DNA-Phosphate Adducts. Chem. Res. Toxicol. 2000, 13, 253-256.

18. Haglund, J.; Henderson, A.; Ehrenberg, L.; Golding, B. T.; Törnqvist, M. A. Evidence for Phosphate Adduct Formation in DNA from Mice Treated with the Tobacco-Specific Nitrosamine NNK. Chem. Res. Toxicol. 2001, 15, 773-779.

19. Haglund, J.; Van Dongen, W.; Törnqvist, M.; Esmans, E. L. Investigation of Capillary Liquid Chromatography Electrospray Ionization Mass Spectrometry and Column Switching for Analysis of Alkyl Cobalamins: A Qualitative Study, unpublished.

20. Crain, P. F. Preparation and Enzymatic Hydrolysis of DNA and RNA for Mass Spectrometry. In Methods in Enzymology, Vol. CXCIII, Chap XLII; McCoy, G. D. Ed.; Academic Press, Inc. Harcourt Brace Jovanovich: London, 1990.

21. McLuckey, S. A.; Van Berkel, G. J.; Glish, G. L. Tandem mass spectrometry of small, multiply charged oligonucleotides. J. Am. Soc. Mass Spectrom. 1992, 3, 60-70.

22. Deforce, D. L.; Ryniers, F. P.; van den Eeckhout, E. G.; Lemière, F.; Esmans, E. L. Analysis of DNA adducts in DNA hydrolysates by capillary zone electrophoresis and capillary zone electrophoresis-electrospray mass spectrometry. Anal. Chem. 1996, 68, 3575-3584. 